\title{
KATALIN KULIN
}

\section{ROL, LUGAR Y CAMINO}

En la Atenas heroica y clásica, así como en la sociedad medieval cristiana, los criterios sobre lo bueno y lo malo se supeditaban a cómo cumpliera la persona su rol en la comunidad: cómo defiende un héroe a su familia, a su tribu, a sus parientes o a sus amigos, cómo derrota a sus enemigos; qué hace el ciudadano ateniense por el bien público; cómo realiza el fiel cristiano la tarea que le corresponde por el sitial que ocupa en la comunidad.

Su rol lo determinaba su propia tribu, el lugar venía dispuesto y señalado por el destino o por Dios. Esta posición podía significar a la vez la primacía del medio dado -el lugar natural o de origen humano- y el sometimiento a un objetivo para cuyo cumplimiento debía recorrer cierto camino.

Para recuperar el lugar que le correspondía hasta antes de ser expulsado por Alfonso VI, el Cid deberá satisfacer las expectativas de la época frente al caballero cristiano, es decir, incrementar el territorio poseído por los cristianos. Sus dotes de excelente, sus virtudes, se medían siempre con respecto a su familia, a los luchadores que se plegaban a él, a la comunidad cristiana encarnada en Alfonso. (Según MacIntyre todas las épocas conservan algo de las virtudes constituidas en los modelos existenciales precedentes. ¿No será que los embustes a los usureros judíos sean simplemente una repercusión de la astucia tan celebrada de Ulises?)

Al final del camino de la vida se conocerá finalmente cuál haya sido la tarea asignada para cada papel. El grado de su cumplimiento ha de ser la medida de la virtud.

El errante Zifar alcanza la corona gracias a sus triunfos y luchas en favor de los agredidos. ( $\mathrm{Y}$ en ese cometido tampoco está limpio de insidias: la fidelidad conyugal a su esposa podrá respetarla en su enlace con la princesa aludiendo a un juramento de abstención hecho por dos años.)

En los dos episodios de Zifar el protagonista llega a un lugar extraordinario. En el primer libro el Caballero Intrépido es llevado por la Señora del Lago a su reino en el fondo de las aguas, mientras que en el tercero, el protagonista Roboán toca con su bote mágico una isla encantada. En las pruebas ambos fracasan, lo que no sorprende ya que no son de allí, no están en terreno propio, no tienen una responsabilidad real frente a los de allí. Por eso no hay ningún castigo para ellos. El Caballero Atrevido es esperado por su gente, mientras que Roboán se casa con Seringa y junto a ella obtiene también el imperio.

Todo el camino recorrido hasta el objetivo no puede verse perturbado por este lugar ubicado fuera del mundo "verdadero", ya que rol y lugar, rol y camino, son elementos indesligables y rigen solamente juntos.

En una de las historias de La gran conquista de Ultramar Isomberta se niega a obedecer a su padre, y escapa. La travesía marina la lleva a un desierto, lugar de la vida solitaria, privada de la comunidad. Su encuentro con el conde Eustacio en el bosque disuelve esa soledad sólo aparentemente puesto que éste se va a la guerra y la 
suegra jamás se llevará bien con la nuera foránea. A pesar de su matrimonio Isomberta no tiene ningún lugar en dicha comunidad. Pagará con la pérdida de sus hijos, es su penitencia por haber dejado su lugar al escapar. La condesa quiere matar a sus hijos para que a través de ellos Isomberta no se incorpore en la comunidad, para que no gane así el derecho a su existencia en su seno, para que no pierda su condición de extraña. A sus hijos los cría en el bosque un ermitaño -este lugar también está fuera de la comunidad humana, como el bosque donde Eustacio había conocido a Isomberta. Es un lugar transitorio: no es el desierto total, pero tampoco un asentamiento humano. De allí puede partir un camino hacia la comunidad, donde luego habrá que mostrar el rol que se asuma, las facultades. Isomberta tendrá su lugar solamente cuando se conoce que sus hijos viven y su marido vuelve a aceptarla. No es nada casual que su hijo, prenda de su pertenencia a la comunidad, se bate por ella y demuestra su virtuosidad, porque la virtud es algo que puede conectarse sólo con el rol desprendido del lugar ocupado en la comunidad.

El heroísmo de Alejandro Magno y sus virtudes cristianas son dignas de reconocimiento - pues la elaboración medieval de su historia ya da cuenta también de tal enfoque- mientras sirven a los intereses helénicos, pero su recompensa es la muerte, en tanto sus objetivos apuntan ya hacia sí mismo: la conquista del mundo entero y la excrutación de los secretos de las profundidades marinas vedadas al hombre, o de la facultad con la que el Creador no dotó al hombre: la experiencia de volar.

Lo que pueda considerarse real es algo supeditado a cada una de las épocas. La realidad del paraíso o del infierno -por más intangibles que sean- no la puso en duda el hombre medieval. Sabía que pasaría a formar parte de una de ellos. El lugar adonde quisiera llegar o evitarlo, donde le espera la felicidad o el sufrimiento eternos.

El hombre temeroso de la condena de Cristo revive en numerosas obras el infierno o a menudo lo describe con fantásticos colores en el marco de un viaje alegórico visto en sueños. Un camino así llevará también a la conversión de Santa María Egipcíaca. En el desierto dará con su verdadero lugar, su verdadero papel. El escenario allí tampoco carece de comunicación: la perfecta convivencia con Dios hace superflua la comunidad humana.

El jardín pletórico de árboles, flores, pájaros y aguas es el lugar de la felicidad anticipada, ansiada y cumplida. Allí se encuentran por primera vez los dos enamorados de Razón de amor, quienes hasta entonces solamente se habían enviado regalos. En el nivel anagógico, la dama que se acerca al joven es la Virgen María. Una vez ida se entiende que estamos asistiendo a una elevación moral por los efectos que el vino y el agua tienen sobre la conducta.

En un jardín maravilloso reposa el exhausto peregrino de Milagros de Nuestra Señora de Gonzalo de Berceo. Este vergel es la recompensa por el camino recorrido, cubre al peregrino con la refrescante frondosidad de la piedad de la Virgen.

El nivel alegórico de estos lugares y rutas peregrinas no reduce la estrecha relación entre lugar, camino y rol. Más allá de simples estancias o viajes, atestiguan que los hechos de sus personajes, su relación con otros, merecieron el lugar ganado por sus plegarias a la Virgen o a Dios. Durante su camino o sus acciones en favor de la comunidad se les abrió la posibilidad de tomar decisiones morales, o sea, decidir entre el bien y el mal. Este bien y mal había de definirse según las acciones en beneficio o perjuicio de los semejantes, de la comunidad, del asentamiento, región o país. La 
calificación del rol, por supuesto, se hace según acerque o no al personaje al logro de su objetivo, a ganarse el cielo.

Durante los siglos XIV y XV hay cierta vacilación sobre esta calificación. En España Juan Ruiz todavía solamente juega con la naturaleza del bien y el mal amor. Que su optimismo provenga de su naturaleza originalmente positiva, o que siguiendo la tradición medieval se trate del optimismo depositado por el pecador en sus esperanzas de piedad, en su confianza en la mediación de la Virgen, no lo sabemos, pero es indiscutible que en el siglo XV se plantean ya las serias interrogantes y dudas sobre el inseguro destino, sobre la muerte ineludible, interrogantes que desvían la atención a la predestinación, un concepto que existía ya también en el dogma católico pero hasta entonces no tan mencionado. Corrobora lo dicho la interrogante planteada por Ferrán Sánchez Calavera sobre el libre albedrío y la predestinación, en relación con la cual se inicia una disputa poética con Pero López de Ayala y otros seis poetas.

Es indudable que Ferrán Sánchez Calavera parte de su propia experiencia, igual que Ausias March o el autor de La Celestina, la obra maestra de fines de siglo.

En estos dos últimos autores, el lugar que puede o debe de deducirse a partir del rol, así como los problemas morales que éste implica, pueden encontrarse no obstante su aparición en espacios indudablemente distintos.

La posición social de Ausias March no podía ser causa de que no encontrara su lugar. Frente a esto, los criados de la Tragicomedia tienen suficientes razones para que valiéndose de las palabras de Celestina no se revuelvan en "casas ajenas", de donde no se librarán hasta no servir con éxito sus propios bienes (VII, auto) puesto que sus amos con sus vanas promesas les chupan la sangre como sanguijuelas (I, acto). La palabra ajeno la utiliza Celestina todavía en su forma general cuando dice ayudar a Pármeno por haberle visto solo en tierra ajena.. Sobre las señoras "de hoy" se manifiesta similarmente Areúsa. En breves palabras: los criados de La Celestina no encuentran su lugar en la casa de sus amos por los cambios ocurridos en las condiciones sociales. Conforme con esto su papel no lo cumplen de la misma manera como lo hicieron sus antecesores en los siglos precedentes.

Las dos palabras destacadas, ajeno y solo, como se verá, son decisivas en Ausias March también sin que su razón la podamos encontrar en las circunstancias sociales.

Espacios concretos apenas si encontramos en la poesía de March. Una que otra metáfora necesita un espacio a modo de señal: la aspre costa, la platja deserta, el mar embravecido (LXXXI,2) de donde los peces escapan a tierra, donde, por supuesto, deben morir, el bosque adonde va a esconderse el ladrón, (VIII,25), el desierto (XXIX), la cárcel, (XVIII), (LIX,29), el aparador que no podrá abrir otra vez la llave que la cerró (II,11). Estos espacios, por supuesto, indican su soledad desesperada, sin esperanzas. Ocurre que directamente a sí mismo se coloca en escena, como por ejemplo "y vaya yo buscando sepulcros" (E vaja jo los sepulcres cercant, XIII), sale del cuarto caliente o va a la nieve, donde los demás están juntos y se sienten bien (LXVIII,12). Se aparta de los demás, él es diferente, un extranjero. El "Sal de la casa extranjera" que la Muerte le dice (Amic, ix de casa estrangera!, XI,12) - hará eco más tarde en el consejo que Celestina le da a Pármeno. Pero en este caso la casa ajena no es la del amo, sino la propia vida. Esta idea la confirma el hecho de calificar a la muerte como su casa: recorro esta casa que es segura (vagabunt vaig la casa qui m'és certa, LXXVI, 7). Se enajena no sólo de la comunidad humana, sino hasta de la pro- 
pia vida también. Este carácter ajeno es entonces metafísico, el individuo enfrentado a su situación existencial.

El excelente estudio de Zimmerman advierte sobre la frecuencia con que March emplea la palabra lugar o un correspondiente locativo. En March no tiene contenido determinado, es una palabra que designa precisamente el vacío; su indeterminación se intensifica ya hasta el absurdo por el adjetivo añadido: incert.

"No encuentro remedio porque es tan grande mi pena, aplastada mi voluntad, no tengo otra opción, ni encuentro la plenitud de mi voluntad en el mismo lugar, sino que tiende tanto hacia la vida como hacia la muerte"(mon voler... ne en sol un loch lo 'm trobe aünit, sino en morir e viure que.s decanta. Tomado de la poesía XXVII). Estas pocas líneas sugieren como si el lugar fuera la vida o la muerte. Mas no cabe duda de que el sentido exageradamente amplio de la vida no permite una delimitación concreta; y la muerte, por otra parte, como no-existencia tampoco puede ser lugar. Y la incertidumbre de la conducta del poeta transforma asimismo en no-lugar el lugar existencial igualmente sin definir.

"Te veo ponerte en mal lugar" (En un mal lloc, amic, vos veig assiure (LII,33), aluden con seguridad a las correlaciones entre lugar y moralidad, lo que claramente se expresa en el verso 31 del poema XXX: porque la virtud está en el lugar del medio (car la virtut en lo mig lloc se met). El lugar del medio en este caso parece estar en clara contradicción con el menosprecio que March pregona contra los enamorados que buscan el lugar central -el camino del medio- en el amor (los que.ls migs llocs en amor van cercant LXIX,11), mientras que él no encuentra el lugar que le corresponde. La causa: no puede amar. "El lugar del amor fracasa en mí" (puis que lo lloc d'amor en mi falli/amor en mi no troba on tenir (XCI,63), y en este mismo poema se queja por no tener lugar seguro sentimiento amoroso ("no té lloc ferm d'amor le sentiment 18") ¿Será él culpable de esto, o acaso el propio amor que invita a tantos placeres que han de satisfacerse en lugar falso? (ssobre lloc fals ha son contentament LXXIX 18). Este incesante interrogarse siempre plantea nuevos puntos de vista, pero el lugar -sea como sea- nunca es el adecuado. Soy (como un torpe) puesto en lugar extraño (en estrany lloc posat CI 7)

"Busco los lugares secretos y evito los públicos", este verso del poema LXXXVII (cerc llocs secrets et los publics desvie 278) atestigua que March se enajena de otros, vive en su medio como extraño; al mismo tiempo demuestra esa búsqueda de lugar siempre latente en toda su poesía, el lugar tan ansiado pero nunca encontrado, el lugar en el cual pueda sentirse en casa y por fin descubrir el secreto de su existencia.

March, en quien todo parece indicar que se acomoda perfectamente según su lugar ocupado en la vida cotidiana y en la sociedad, no encuentra su lugar en las capas internas y profundas de su personalidad. Por eso es inseguro, por eso contradice todas sus afirmaciones, por eso es incapaz de alcanzar la virtud, la virtud cuya verdadera medida podría provenir del lugar encontrado en la relación interpersonal.

Esto es lo que aúna su poesía amorosa y religiosa: busca su lugar en el cual encontraría su rol y este rol le orientaría y le daría la capacidad de escoger, y a su voluntad no sólo que le señalaría un rumbo sino lo afianzaría, y por fin el voler -vocablo que en la Edad Media significaba todavía tanto amor como voluntad- sería ferm, seguro.

Los poetas provenzales divinizaban a sus damas, pero la distancia entre ellos y la mujer adorada ya de por sí indica que a ellos les interesaba el amor y en esto la mujer 
escogida no pasaba de ser un pretexto. En otras formas de su poesía: tenso, partiment, etc., señalan pertenecer a cierto grupo o capa de la sociedad medieval, y según estos intereses arremeten contra los grandes señores, amantes o poetas rivales. Bertrand de Born ensalza la guerra en uno de sus poemas y alude al placer que le invade al ver el campo de batalla regado de enemigos muertos. El trovador respondía con las armas al desafío de hombre o enemigo; si le maravillaba la admiración por una dama excelente, bella y distinguida recurría a la poesía y en ella analizaba sus sentimientos. Obtenía más conocimientos en el campo de batalla y profundizaba mejor en su propio mundo interno. Al satisfacer el rol correspondiente a su lugar empezó a conocerse y formarse a sí mismo. De ahí la inmensurable importancia que la poesía trovadoresca tiene para la civilización europea.

El propio hecho de que la lira provenzal se institucionalizó demuestra su carácter social. Aunque Ausias March aparentemente siga las tradiciones provenzales, no tiene nada que ver con su mundo afectivo institucionalizado. March como enamorado no pertenece a ningún grupo social y no sigue ninguna norma establecida. No es convencional, puesto que ello implicaría la pertenencia a los otros, pero él, el extraño, aunque lo reconozca, no puede considerarse obligado a los puntos de vista o formas de comportamiento de los demás. Su carácter de extraño es singular. ¿Con respecto a qué es extraño? No puede serlo con respecto a su medio, donde su lugar está exactamente delimitado y en el que él incluso encaja. Él se ha alejado de las convenciones espirituales de la sociedad no en su realidad social sino en su espíritu. Conoce bien a Lulio, Aristóteles, Tomás de Aquino, pero en sus postulados no puede obtener una respuesta que disipe todas sus dudas. Anhela la seguridad en la fe de la Edad Media pero la fe ya no es obvia para él; debido a sus dudas se aleja de la comunidad cristiana, se autocalifica de extranjero porque no encuentra allí su lugar. Sus decisiones no hacen que él cumpla con su rol de manera digna a un cristiano. March espera un rol que logre su cometido en la relación directa con Dios. Esta relación directa difiere de la conducta cristiana tradicional, esta es la manifestación de la individualidad que apunta hacia la nueva época. Por eso podemos hablar de la modernidad de March.

Mas esta modernidad cuesta mucho. No hay normas por seguir, ya que quien se relaciona directamente con Dios recibe de Dios la orientación, pero, por supuesto, no puede percibirlo así si su fe es débil, si se siente lejos de él, si en el lugar de la relación personal ha penetrado lo extranjero. Las normas anteriores pierden vigencia y la causa del tormento es doble porque no obstante la falta de vigencia no queda otra norma digna de crédito. March busca correctamente la solución en la plenitud del amor, trátese de su amor o de su fe. El amor rige para ambos aspectos de la caridad, por eso hay cierta continuidad entre la poesía amorosa y los poemas divinos de March. A falta de un amor que los aúne, el yo en sí mismo indagará por su medida, pero la lucha que libra por la relación perfecta ha afianzado su autoconocimiento hasta el punto de creer en la condición suficiente de su propia medida y de su propia moralidad. El telos conformado por el ejercicio de la vida es inseguro, penumbroso: un amenazador lugar misterioso y oscuro donde no sólo la crueldad sino hasta el arrepentimiento imprescindible para el perdón, la luz de la contrición, tampoco alumbra el camino de la salvación, donde los muros de la atrición, del remordimiento sin verdadero arrepentimiento, hacen definitiva la soledad. 